\title{
Long-Term Performance of Engineered Concrete Barriers
}

J. R. Clifton James M. Pommersheim Kenneth Snyder

July 1995

Building and Fire Research Laboratory

National Institute of Standards and Technology

Gaithersburg, MD 20899

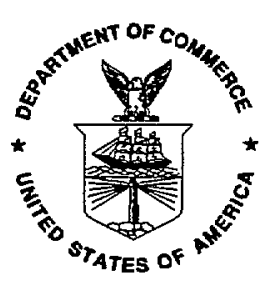

U.S. Department of Commerce

Ronald H. Brown, Secretary

Technology Administration

Mary L. Good, Under Secretary for Technology National Institute of Standards and Technology Arati Prabhakar, Director 

LONG-TERM PERFORMANCE OF ENGINEERED CONCRETE BARRIERS by

James R. Clifton ${ }^{a}$, James M Pommersheim ${ }^{b}$, and Kenneth Snyder ${ }^{a}$

\begin{abstract}
This paper describes research being carried out at NIST on the long-term performance of concrete for constructing lowlevel nuclear waste (LLW) disposal facilities. These studies have included identification of likely major degradation and cracking processes, evaluation and development of accelerated degradation test methods, and the analysis and development of mathematical models for service life predictions. The major degradation processes that underground concrete will likely to encounter are sulfate attack, corrosion of reinforcing steel, alkali-aggregate reactions, and leaching by ground water. Major cracking processes in immature concrete, such as plastic shrinkage, plastic settlement, and early thermal expansion/contraction should occur before the vault is covered. Cracks caused by drying shrinkage, thermal and moisture expansion/contraction are less likely to occur once a vault is covered. Load-induced cracks can be avoided by proper design and construction practices.
\end{abstract}

Degradation processes which would likely be active above ground, but not below ground, or to be significantly more severe above ground, include freezing and thawing, drying shrinkage, cracking due to thermal and moisture expansion/contraction of concrete, abrasion by wind driven particulate matter, and impact by wind driven objects.

Three major research needs have been identified which are: validation of service life models; development of performance criteria for materials and systems to repair concrete before closure of concrete vaults; and development of an expert system to dissiminate knowledge on concrete durability for constructing concrete vaults.

Keywords: concrete; corrosion; leaching; low-level nuclear disposal; modeling; service life; sulfate attack

a Building and Fire Research Laboratory, National Institute of Standards and Technology Gaithersburg, MD 20899

b Bucknell University

Lewisburg, PA 17837 

TABLE OF CONTENTS

Page

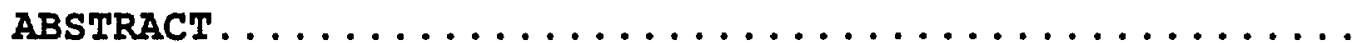

1. INTRODUCTION.........................

2. DETERIORATION PROCESSES FOR UNDERGROUND CONCRETE... 1

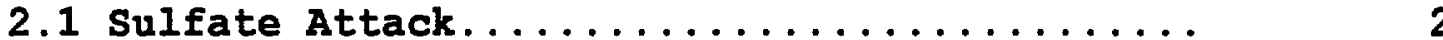

2.1 .1 Mechanisms of Sulfate Attack........ 2

2.1 .2 Kinetics of Sulfate Attack.......... 2

2.1.3 Sulfate Diffusion Coefficient........

2.2 Corrosion of Reinforcing steel............. 4

2.2.1 Corrosion Mechanisms............... 4

2.2.2 Service Life when Corrosion is the

2.2.3 Chloride Diffusion Coefficient.......

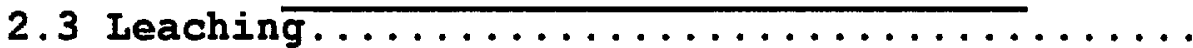

2.3.1 Mechanisms..................

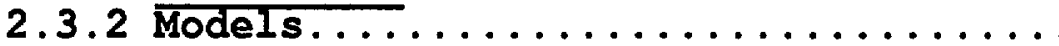

2.4 Alkali-Aggregate Reaction.............. 6

2.4.1 Prevention of Alkali-Aggregate

Expansive Reaction............. 6

2.4.2 Determination of Alkali-Carbonate

Reactivity................ 7

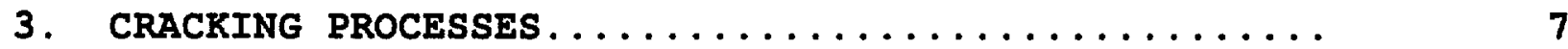

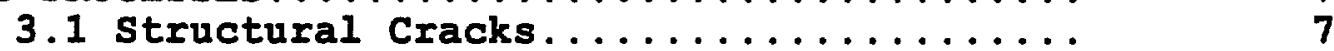

3.2 Intrinsic cracks................. 8

4. DEGRADATION PROCESSES FOR ABOVE GROUND CONCRETE.... 9

5. QUALITY OF CONCRETE..................... 9

6. RECOMMENDATIONS ....................... 9

7. SUMMARY............................ 10

8. ACKNOWLEDGMENTS ....................... 11

9. REFERENCES .......................... 11 
$-$

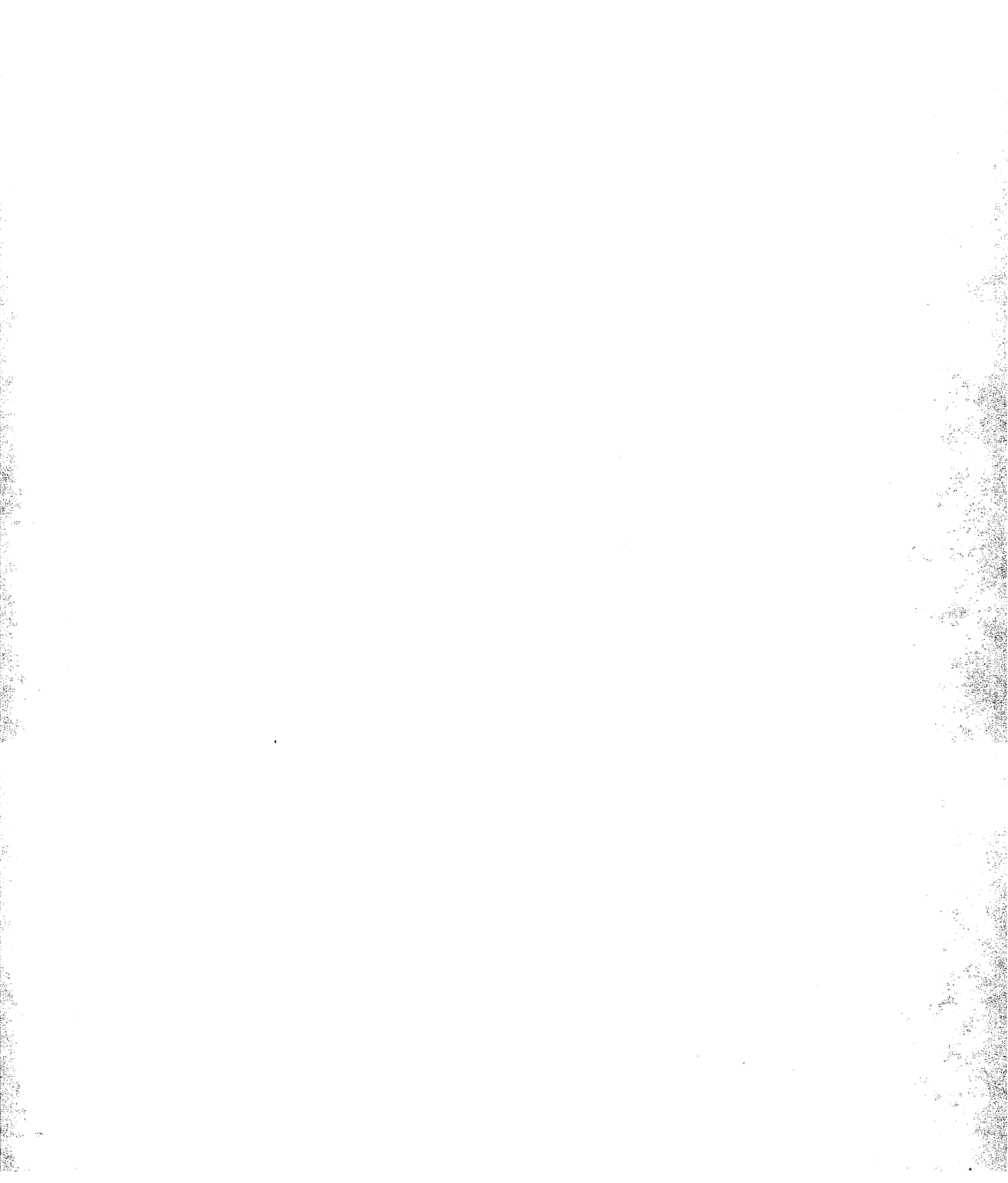

$\therefore \quad$
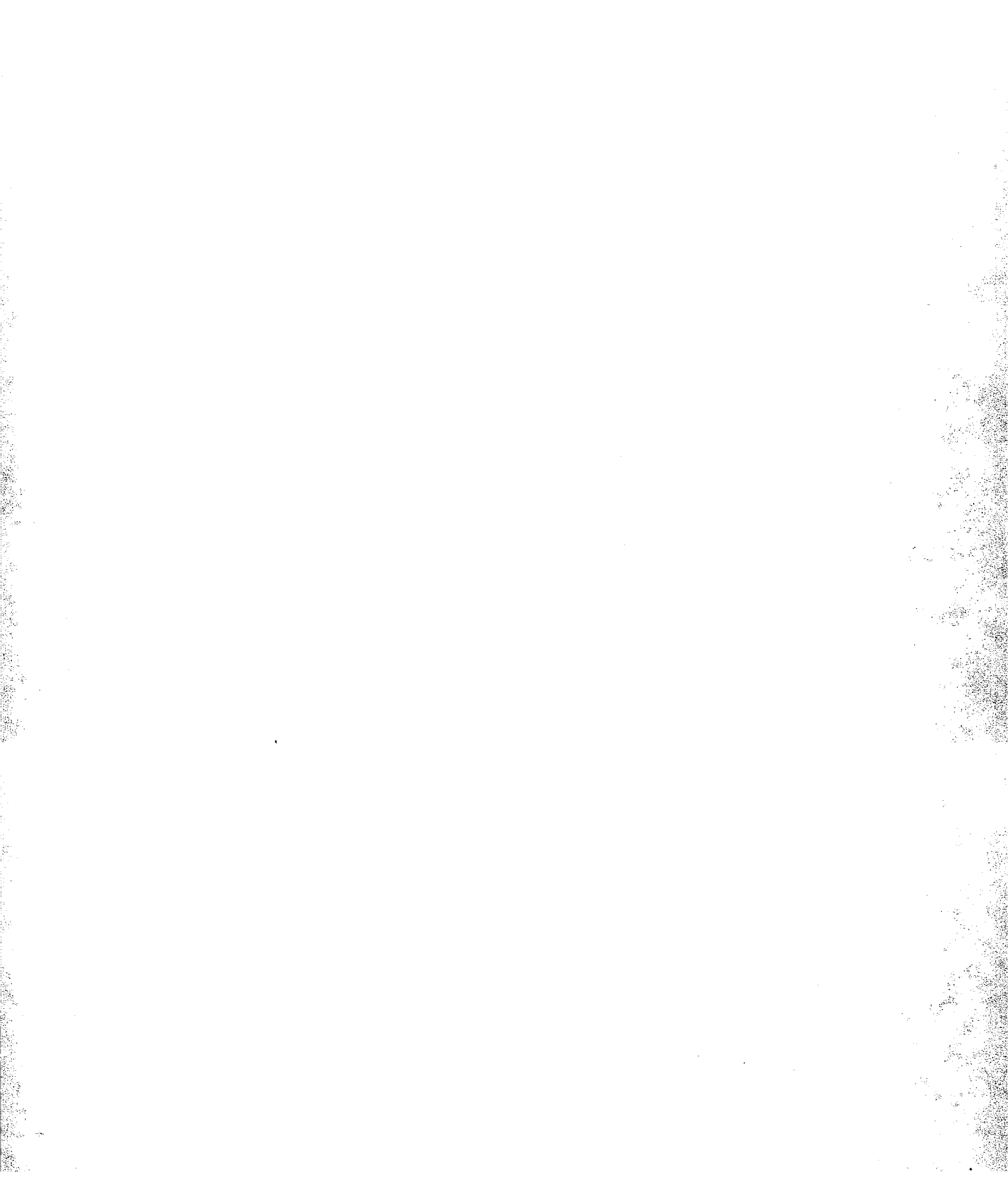


\section{INTRODUCTION}

Engineered barriers constructed of concrete will likely replace shallow landfill trenches for disposal of LLW. Implicit in the technical requirments and the long term performance objectives of NRC regulations $10 \mathrm{CFR} 61$ is the need that concrete-based structural members for an engineered LLW waste disposal have a reasonable assurance of having a service life of 500 years [1]. The end of the service life can result from one of two conditions: (1) loss of load-bearing capacity; or (2) increase in the hydraulic conductivity of the concrete so that an unacceptable flow of water can occur through the structure. The present basis for selecting concrete and its constituents needs to be advanced to ensure that concrete vaults for LLW disposal can be constructed with the reasonable expectation they will fulfill this service life requirement. At least two approaches can be followed [2]. In the first, the most durable concrete could be developed using expert judgement based on accumulative knowledge from laboratory and field testings, and heuristics. This method gives an "assumed service life" prediction. The concrete may perform adequately for its service life, especially if the design life is short (no longer than around the career of a concrete expert, e.g., 50 years) and the exposure conditions are not too severe. This approach breaks down when it becomes necessary to predict the service life of concrete which must be durable for a time that exceeds our experience with concrete, when new environments are encountered, or when new concrete materials are to be used. In the other approach, performance criteria are developed based on considerations of the factors controlling the service life of concrete. The latter approach $[3,4]$ involves the identification of the anticipated important deterioration processes; elucidation of their mechanisms; use, and if necessary, development of accelerated tests; and application of mathematical models. This approach is being followed in a project at the National Institute of standards and Technology (NIST), sponsored by the U.S. Nuclear Regulatory (NRC) Commission on concrete engineered barriers for LLW disposal. This paper describes the research being carried out at NIST on the long-term performance of concrete for constructing LLW disposal facilities.

\section{DETERIORATION PROCESSES FOR UNDERGROUND CONCRETE.}

In many ways, an underground environment below the frost depth should be favorable for concrete longevity as temperature and moisture variations should be minimal, significantly reducing the potential of cracking due to drying shrinkage and thermal

expansion and contraction. Frost damage should only occur before the concrete vaults are covered with soil. However, if the vault will be uncovered and exposed to freezing temperatures it should 
be protected from ponding water as well as being entrained with the recommended amount of air with the recommended air bubble spacing [4]. The major degradation processes that underground concrete will likely to encounter [4] are sulfate attack, corrosion of reinforcing steel, alkali-aggregate reactions, and leaching by ground water. The factors controlling the severity of the degradation processes are given in Table 1. Other degradation processes which are considered to be less likely to have a serious effect are microbiological attack, salt crystallization attack, and attack by LLW, especially those containing acids.

\subsection{Sulfate Attack}

Probably the most widespread and common attack of concrete in soils involves sulfate salts. Naturally occurring sulfates of sodium, potassium, calcium, and magnesium are found in ground water and soils. Also, the internal surfaces of concrete vaults can be subjected to attack by sulfate-containing LLW.

\subsubsection{Mechanisms of Sulfate Attack}

Although sulfate attack has been the subject of extensive research [5] its mechanism has not been unequivocally identified. Until recently, sulfate attack was thought to involve internal stress development resulting from the formation and filling of pores and voids by gypsum and ettringite. However, modelling at NIST [6] has revealed that more than sufficient capillary pore space is available in normal concrete to accompany the formation of gypsum and ettringite. The formation of ettringite does appear to lead to degradation of concrete but apparently by an indirect process. Recent studies $[7,8]$ suggest that sulfate attack may degrade concrete by causing the decalcification of $\mathrm{C}-\mathrm{S}-\mathrm{H}$, the major binding component of hydrated portland cement. According to this proposed mechanism, the calcium hydroxide released by the degradation of $\mathrm{C}-\mathrm{S}-\mathrm{H}$ reacts with soluble sulfate ions, and monosulfate $\left(3 \mathrm{CaO} \cdot \mathrm{Al}_{2} \mathrm{O}_{3} \cdot 12 \mathrm{CaSO}_{4}\right)$ to form ettringite $\left(3 \mathrm{CaO} \cdot \mathrm{Al}_{2} \mathrm{O}_{3} \cdot 3 \mathrm{CaSO}_{4} \cdot 32 \mathrm{H}_{2} \mathrm{O}\right)$. As $\mathrm{C}-\mathrm{S}-\mathrm{H}$ degrades, the moduli of elasticity of the concrete is reduced and less stress is required to cause expansion and cracking.

\section{1 .2 Kinetics of Sulfate Attack}

NIST has been carrying out studies on the kinetics of sulfate attack based on accelerated tests and mathematical modeling. Expansion of mortar bars exposed to aqueous solutions of sodium sulfate were measured following the procedures of ASTM C 1012 [9]. As anticipated, it was observed that as the tricalcium aluminate $\left(C_{3} A\right)$ content of the cement increased, the rate of expansion of the mortar bars increased (Figure 1). The expansion curve for mortar bars made with cement having a $\mathrm{C}_{3} \mathrm{~A}$ content of $6 \%$, exposed to a $5 \%$ solution of $\mathrm{Na}_{2} \mathrm{SO}_{4}$, is shown in Figure 2 . It consists of two stages, with stage 1 ending at $t_{0}$. If the bars are allowed to continue to expand in stage 2 they eventually 
exhibit a form of map cracking and subsequently fall apart.

The expansionsiwere fitted to the model:

$$
X=K t^{n}
$$

where $\mathrm{X}$ is expansion,

$K$ is a constant,

$t$ is time, and

$\mathrm{n}$ is the time order.

The time orders for the two stages were obtained by plotting the log of expansion versus the log of time, as described by clifton and Pommersheim [10]. Values of $n$ close to $1 / 2$ denote a diffusion controlled process, whereas $n$ greater than 1 indicates that the degradation process is controlled by a volumetric increase induced by microcracking. Other models have been developed for predicting the kinetics of concrete subjected to sulfate attack. A shrinking core model [11] has been developed, which is based on the hypothesis that diffusion of external sulfate ions into concrete controls the rate of degradation, however, it did not consider the existance of a stage 2. Atkinson and Hearne [12] developed a mechanistic model in which the rate of degradation is predicted to be reaction controlled, with $\mathrm{n}=$ 1. Based on interpretation of the studies of mortar bars exposed to sulfate containing solutions, it appears that both the diffusion coefficient of sulfate ions and the $C_{3} A$ contents of the cement have major influences on the life of concrete exposed to deleterious amounts of sulfate ions. Although it predicts a different time order, the mechanistic model [12] agrees with the predicted general effects of the sulfate diffusion coefficient and $C_{3} A$ contents.

2.1.3 Sulfate Diffusion Coefficient

The above kinetic models predict that a 10-fold increase in the diffusion coefficent of sulfate will result in a 10-fold decrease in the service life of concrete. Therefore, representative estimates of sulfate diffusion coefficients are needed to make reasonable life predictions. However, measurements of sulfate diffusion coefficients in concrete are difficult because calcium sulfate is blended with clinker during grinding to control the set time of the cement. A relationship for estimating the sulfate diffusion coefficients of concrete based on chloride ion coefficients was derived [13]. The chloride diffusion coefficient of concrete can be more readily measured than the sulfate ion coefficient. For a given water-to-cement ratio $(w / c)$, the sulfate diffusion coefficient is about an order of magnitude less than the diffusion coefficient for chloride ions. The lower diffusion coefficient for sulfate ions is largely 
attributable to its reactivity with calcium hydroxide to form gypsum, and monosulfate to form ettringite.

\subsection{Corrosion of Reinforcing steel}

\section{2 .1 Corrosion Mechanisms}

Corrosion of reinforcing steel in underground concrete can be caused by chloride ions, carbonation, or stray currents. A conceptual model [14] for corrosion induced by chloride ions or carbon dioxide is presented in Figure 3. According to this model, corrosion starts after the end of an initiation period followed by a propogation period of active cracking. The initiation period involves the transport of chloride ions to the depth of the reinforcing steel at a sufficient concentration (threshold concentration) to depassify the steel; or by cabonation which reduces the $\mathrm{pH}$ of the pore solution in contact with the steel; or by the synergetic effect of chloride ions and carbonation. Carbonation is usually a problem with reinforced in which the reinforcement is closer to the surface of the concrete than recommended and with high-porosity concrete. Also, if the concrete is saturated, the ingress of carbon dioxide is very slow because of its low solubility in water. The rate of corrosion occurring in the propogation period is controlled by the diffusion of oxygen to the steel surface, resistivity of the pore solution, and temperature. When sufficient corrosion products are formed, the resulting stresses exceed the tensile strength of the concrete and cracking occurs.

\subsubsection{Service Life when Corrosion is the Limiting Process}

Usually the initiation period is much longer than the propogation period and thus only its duration is used in making service life predictions. Assuming that diffusion is the principle transport process, the major factors controlling the predicted service life, therefore, are the diffusion coefficients of chloride ions and carbon dioxide, their concentrations in the soil or ground water, and the depth of concrete over the reinforcing steel. Their effects on chloride ion induced corrosion are given in Table 2. The chloride ion diffusion coefficient of good quality concrete should, with $a \mathrm{w} / \mathrm{c}$ of 0.40 , be around $3.5 \times 10^{-12} \mathrm{~m}^{2} / \mathrm{s}$. If corrosion is caused by carbonation, it will likely be much slower compared to chloride ions because of the low solubility of carbon dioxide in pore water of concrete and because it is consumed in neutralizing the calcium hydroxide produced by hydration of cement, as well as reacting with other hydration products.

\subsubsection{Chloride Diffusion Coefficient}

As with sulfate attack, a 10-fold increase in the diffusion coefficent of chloride ions will result in a 10 -fold decrease in the initiation period and thus the predicted service life of concrete. Therefore, representative estimates of chloride diffusion coefficients are needed to make reasonable life 
predictions. At present a standard test does not exist for measuring the chloride diffusion coefficient of concrete. A potential standard test method for measuring chloride diffusion is being developed [15] using impedence spectroscopy techniques.

\subsection{Leaching}

\subsubsection{Mechanisms}

Water percolating through soils can dissolve soluble materials in concrete and gradually result in its degradation. While instances of complete degradation of concrete by leaching are rare, leaching can render the matrix more porous and thereby increase the transport properties of concrete. Also, dissolution of calcium hydroxide can reduce the $\mathrm{pH}$ of concrete, thereby promoting corrosion of the reinforcing steel.

Leaching of concrete is dependent on the chemistry and flow rate of the ground water and the transport properties of the concrete. Calcium-absortive acidic ground waters are especially aggressive to concrete [16]. Leaching possibly could become a significant problem for concrete above the maximum water table, if sufficient drainage water is percolating through the engineered soil barrier.

\section{3 .2 Models}

Models for leaching and carbonation are characterized by a moving interface which separates a leached from an unleached zone. They are based on the presumption that the concrete is saturated and the effects of convection or hydraulic flow can be neglected. These conditions are reasonable up to the time that cracks percolate through the concrete or when it has lost structural capacity.

Leach models have the common form:

$$
X_{i}=\left[\frac{2 D_{i} \Delta C_{i}}{m V_{B} M_{B}} t\right]^{1 / 2}
$$

where

$$
\begin{aligned}
& \mathrm{X}_{\mathrm{i}} \quad=\text { depth of penetration, } \mathrm{cm} \\
& t \quad=\text { exposure time, yr } \\
& \Delta \mathrm{C}_{\mathrm{i}} \quad=\text { concentration difference of species } i \text { between } \\
& \text { the interface and the groundwater outside the } \\
& \text { concrete, gmol/liter } \\
& \mathrm{m}=\text { moles of acid (A) which react with one mole of } \\
& \text { base (B) } \\
& \mathrm{V}_{\mathrm{B}} \quad=\text { bulk volume ratio (CC solid } \mathrm{B} / \mathrm{Cc} \text { concrete) } \\
& \mathrm{M}_{\mathrm{B}} \quad \text { = molar density of solid } \mathrm{B} \text { (gmol } \mathrm{B} / \text { liter of } \mathrm{B} \text { ) } \\
& \mathrm{D}_{\mathrm{i}} \quad=\text { intrinsic diffusivity of } \mathrm{i} \text { in concrete, } \mathrm{cm}^{2} / \mathrm{s}
\end{aligned}
$$


Eq. (2) is a generalization of standard diffusion controlled leaching models. As with all such models it predicts that $x_{i}$ varies as $t^{1 / 2}$. In eq. (2), i represents the rate limiting species. For calcium hydroxide leaching by neutral ground water it is the calcium ion.

Service life can be defined as the time taken for the interface to advance some critical distance $x_{i c}$ across the concrete element. For leaching, concrete which has lost $1 / 3$ of the solid calcium hydroxide is considered to be degraded and no credit should be given this degraded concrete when calculataing the residual load capacity of the concrete element. Therefore, the effect of leaching will be to reduce the thickness of the concrete element, $L$, by $x_{i}$. The magnitude of $x_{i c}$ will depend on the structural design of the concrete element.

The application of eq. (2) predicts that if the groundwater has a zero concentration of calcium ions or the reinforcing steel bars are close to the concrete surface, leaching may have significant effects on the performance of concrete within 500 years [4]. The same model indicate that low porosity concrete with proper depth of cover over reinforcing steel, located in the unsaturated zone exposed to groundwater with a positive Langlier Index [17], should not be significantly effected by leaching within 500 years. The Langlier Index is related to the total solids, total alkalinity, $\mathrm{pH}$, and calcium content of the water. A positive value indicates that calcium carbonate will be precipitated; a negative index indicates Iime-deficient water capable of dissolving calcium from hardened cement paste.

\subsection{Alkali-Aggregate Reactions.}

Most aggregates appear to react to some degree with alkalies in concrete [4]. Usually the reactions are beneficial, e.g., increasing the bond between aggregate and hydrated cement, or innocuous. In some cases, however, the reactions result in the formation of expansive products which can cause cracking of the concrete. The expansion is attributed to the imbibition of water by the reaction products. When cracking occurs its effects can range from being cosmetic (in most cases) to resulting in structural failure (uncommon) of concrete. Even if the cracking is cosmetic in nature, it can significantly increase the hydraulic conductivity of the concrete.

2.4.1 Prevention of Alkali-Aggregate Expansive Reactions The best approach to avoid alkali-aggregate expansive reactions is to selected unreactive aggregates. Low alkali cements can be used, however, soils contain some alkalies which can accumulate thereby increasing the alkali content of concrete [4]. Also, some aggregates can release alkalies. Often reactive aggregates are used by adding pozzolanic materials to the concrete. While 
this approach appears to mitigate expansive reactions for many years, the effectiveness of pozzolans over some 500 years is uncertain. Carbonate aggregates, pure as possible, are recommended as $\mathrm{CaCO}_{3}$ does not react to form deleterious expansive gels with alkalies.

All siliceous aggregates are reactive, to some extent, in the presence of alkalies [4] and thus should not be used in concrete of LLW disposal vaults. The apparent unreactivity of most siliceous aggregates can be attributed to kinetically-controlled reactions, the rates of which, at present, cannot be predicted over some 500 years. Recently, the addition of lithium salts has been reported [18] to prevent deleterious expansions from alkalisilica reactions. Apparently, the lithium cation reacts with silica to form non-expansive gels. The long-term effectiveness of such salts have not been demonstrated by field use. Also, low water-to-cement concrete with an extremely low permeability may retard the rate that water is imbibed by the reaction products.

\subsubsection{Determination of Alkali-Carbonate Reactivity}

Decisions on the potential alkali reactivity of a carbonate aggregate are sometimes based on its service records performance. However, even if service records are available which indicate that the aggregate appears to be unreactive, laboratory examination and testing should be performed. The source of aggregates have changed over the years and it is doubtful that sufficient long-term service records exist to form a base for predicting that carbonate aggregates will be free from expansive reactions for some 500 years.

Potentially reactive limestones can be identified by petrographic examination and composition determination [19], and the rock cylinder test and the concrete prism test according to the procedures given in ASTM C 586 [20] and ASTM C 1105 [21], respectively. Criteria for determining if a carbonate aggregate is unreactive are being developed by NIST.

\section{CRACKING PROCESSES}

Concrete cracks occur as two general types: (1) structural cracks induced by loads, foundation shifting, seismic events, impact and other types of physical and mechanical stress loads; and (2) cracks caused by internal stresses due to volumetric expansion or shrinkage occurring within the concrete.

\subsection{Structural cracks.}

Structural cracks are often caused by poor design and construction and should not occur if a proper quality control and quality asssurance program is implemented. A structural analysis is required to determine the probability of the occurence of 
structural cracks. While the effects of seismic events can not be predicted, conforming to the current building codes should give a reasonable probability that the structural should survive (i.e. not collapse) the designed-for event. However, conforming to the building codes will not insure that cracks will not develop and significantly increase the hydraulic conductivity.

\subsection{Intrinsic Cracks.}

Cracks caused by dimensional changes can be further separated into two classes: (1) those which are intrinsically sustained by the nature of the constituent materials, which can occur when concrete is in either the plastic or hardened state, such as plastic shrinkage and long-term drying shrinkage; and (2) those caused by degradation processes as previously discussed.

The major types of intrinsic cracks are [22]:

(a) cracks occurring when concrete is plastic or immature: *plastic shrinkage

*plastic settlement

*early thermal cracking

(b) cracking occurring in mature concrete: * creep

*thermal expansion/contraction

*moisture expansion/contraction (drying shrinkage).

Cracks occurring when concrete is in the plastic state or is immature are caused by poor construction practices. Both plastic shrinkage and plastic settlement cracks can be corrected when the concrete is still in a plastic state. The potential occurrence of early thermal cracking is dependent on several factors including weather conditions, type of form material used, and properties of the concrete materials. Early thermal cracks are usually not deep, unless the concrete element is severely restrained from movment, and are visible within a month or so after construction.

Drying shrinkage and thermal expansion are the major reason that joints are necessary. Drying shrinkage and thermal expansion/contraction are the processes most likely to cause cracks in mature concrete of LLW disposal vaults [4]. When a vault is covered with soil, such cracks are unlikely to occur as the moisture and temperature conditons of the concrete will then remain fairly constant. However, they could be a recurring problem with above ground concrete. The potential of drying shrinkage occurring in concrete vaults is discussed by carino and clifton [23]

4. DEGRADATION PROCESSES FOR ABOVE GROUND CONCRETE

The same degradation processes that affect the performance of 
underground concrete also can be deleterious to above ground concrete. Many of the processes in Table 1, require the movement or presence of water in concrete and thus they could potentially be more active above ground. Sulfate attack would likely to be a major problem only for the foundation or for that portion of engineered barriers immediately above the gradeline. Degradation processes which would likely to be active above ground, but not below ground, or to be significantly more severe above ground, include freezing and thawing, drying shrinkage, cracking due to thermal and wet/drying expansion and contraction of concrete, abrasion by wind driven particulate matter, and impact by wind driven objects.

\section{QUALITY OF CONCRETE}

The performance of a concrete structure is usually no better than the quality of its materials and construction practices. The need for quality concrete increases directly with the severity of requirements placed on its performance. clearly, the requirement that concrete to be used to construct storage vaults for LLW must be durable for 500 years, is a severe demand necessitating that close attention is given to the factors controlling its quality [4] - Many construction practices will affect the quality of inplace concrete used for constructing engineered barriers for LLW disposal, including the selection and proportioning of concrete materials; the placement of forms and reinforcement; the mixing, consolidating and curing of concrete; and the proper testing of the concrete. Also, after a structure is complete, the hardened concrete should be inspected to determine if the design specifications for it are met. In addition to the traditional strength measurments, the permeability, or other some measurment of the durability of the in-place concrete should be made. To ensure that hardened concrete gives the desired performance, a quality management program should be implemented. It should include establishing requirements for quality, for the testing of quality, and for quality auditing of the completed structure.

\section{RECOMMENDATIONS}

We feel that in addition to the work which presented in this paper, that work should be carried out on the following three areas; validation of service life models; development of performance criteria for materials and systems for repairing concrete before closure of concrete vaults; and development of an expert system to dissiminate knowledge on concrete durability.

Predictions of the long-term performance of concrete for LLW disoposal are primarily based on service life models, whose reliability should be validated. A recommended approach for making such validations involves studies of aged concretes whose 
composition, properties, and service environment has been or can be documented. By comparing the concretes' conditions with those predicted by appropriate models a basis for judging the reliability of the models could be established.

If LLW concrete vaults are buried underground, the majority of intrinsic cracking will take place before the vaults are covered with an engineered barrier system. These cracks can be identified and if necessary repaired before the vaults are covered. However, the repair material should have the same service life as the bulk concrete. At present a basis does not exist for predicting the long-term performance of concrete repair materials. We recommend that performance criteria be develop for materials to repair cracks in the concrete vaults.

We recommended that an expert system be developed to capture and dissiminate the knowledge resulting from the various studies on the durability of concrete for constructing vaults for LLW. The principles, development methods, and applications of expert systems for concrete construction have been described by clifton and Kaetzel [24]. It would give recommendations on the selection of concrete materials and the mix design based on the anticipated service environment.

\section{SUMMARY}

The studies at NIST have concentrated on the prediction of the long-term performance of concrete for constructing engineered barriers for LLW disposal. These studies have included identification of likely major degradation and cracking processes, evaluation and development of accelerated degradation test methods, and the analysis and development of mathematical models for service life predictions. The major degradation processes that underground concrete will likely encounter are sulfate attack, corrosion of reinforcing steel, alkali-aggregate reactions, and leaching by ground water. Cracking may result in increasing the hydraulic conductivity of the concrete. Intrinsic cracks caused by such processes as plastic shrinkage, plastic settlement, and early thermal expansion and contraction should occur before the vault is covered. Cracks caused by drying shrinkage and thermal expansion and contraction are less likely to occur once a vault is covered as the moisture and thermal conditions will be relatively constant. Structural cracks can be avoided by proper design and construction practices.

Degradation processes which would likely be active above ground, but not below ground, or to be significantly more severe above ground, include freezing and thawing, drying shrinkage, cracking due to thermal and wet/drying expansion and contraction of concrete, abrasion by wind driven particulate matter, and impact by wind driven objects. 
The performance of concrete for constructing engineered barriers will depend to a great extent on the quality of the construction processes. Many construction practices will affect the quality of in-place concrete used for constructing engineered barriers for LLW disposal and should be addressed in a quality management program. The quality program should including establishing requirements for quality, for the testing of quality, and for quality auditing of the completed structure.

Three major research needs have been identified which are: validation of service life models; development of performance criteria for materials and systems to repair concrete before closure of concrete vaults; and development of an expert system to dissiminate knowledge on concrete durability for constructing concrete vaults.

\section{ACKNOWLEDGEMENTS}

The authors wish to acknolwedge the financial suppoprt of the U.S. Nuclear Regulatory Commission (NRC) for this research. Mr. Jacob Philip was the program manager and his advice is greatly appreciated.

\section{REFERENCES}

1. J. Philip and J.R. Clifton, "Concrete as an Engineered Alternative to Shallow Land Disposal of Low Level Nuclear Waste: Overview," in Fly Ash, Silica Fume, Slag, and Natural Pozzolans in Concrete: Proceeding Fourth International Conference, ACI SP-132, pp. 713-730, 1992 .

2. J.R. Clifton, "Predicting the Service Life of Concrete," ACI Materials Journal, V. 90 (6), pp. 611-617, 1993.

3. J. Pommersheim and J.R. Clifton, "Prediction of Concrete Service-Life," Materials and Structures, V. 18 (108), pp. 2130,1985 .

4. J.R. Clifton and L.I. Knab, "Service Iife of Concrete," Report No. NUREG/CR-5466, U.S. Nuclear Regulatoray Commission, Washington, D.C., 1989 .

5. P.K. Metha, "Sulfate Attack on Concrete-A Critical Review," in Materials Science of Concrete III, J. Skalny ed., pp 105-130, American Ceramic Society, 1992. 
6. J.R. Clifton, and J. Pommersheim, "Sulfate Attack of Cementitious Materials: Volumetric Relationships and Expansions," NISTIR 5390, National Institute of standards and Technology, Gaithersburg, MD, 1994.

7. R.S. Gollup and H.F.W. Taylor, "Microstructural and Microstructural studies of Sulfate Attack. I. Ordinary Portland Cement Paste, "Cement and Concrete Research, V. 22, pp. 1027-1038, 1992 .

8. J.M. Pommersheim and J. R. Clifton, "Expansion of Cementitious Materials Exposed to Sulfate Solutions, "Materials Research Society Proceedings, V. 333, pp. 368, 1993.

9. "Standard Test Method for Length Change of Hydraulic-Cement Mortars Exposed to a Sulfate Solution," ASTM Designation C 1012, Philadelphia, 1993.

10. J.R. Clifton and J.M. Pommersheim, "Methods for Predicting Remaining Life of Concrete in Structures," NISTIR 4954, National Institute of Standards and Technology, Gaithersburg, MD, 1992 .

11. A. Rasmuson and M. Zhu, "Calculation of the Degradation of Concrete in a Final Repository for Nuclear Water," in Proceedings of NEA Workshop on Near-Field Assessment of Repositories for Low and Medium Level Radioactive Wastes Baden, Switzerland, 1987.

12. A. Atkinson and J.A. Hearne, "Mechanistic Model for the Durability of Concrete Barriers Exposed to Sulphate-Bearing Groundwaters," Materials Research Society Symposium Proceedings, 176, pp. 149-156, 1990.

13. J.R. Clifton, D.P. Bentz, and J.M. Pommersheim, "Sulfate Diffusion in Concrete," NISTIR 5361, National Institute of Standards and Technology, Gaithersburg, MD, 1994.

14. K. Tuttii, "Corrosion of steel in Concrete," Swedish cement and Concrete Research Institute, Stockjolm, 1982.

15. K.A. Snyder and J.R. Clifton, "Calculating Cement Paste and Mortar Diffusivity from Conductivity Measurements: Preliminary Results of a New Test Method," NISTIR 5235, National Institute of Standards and Technology, Gaithersburg, MD, 1993 .

16. W.G. Hime, B. Erlin, and R.R. Mcormand, "Concrete Deterioration through Leaching with Soil Purified water," Cement, Concrete, and Aggregates, V. 8 (1), pp. 50-51, 1986. 
17. W.F. Langelier, "The Analytical Control of Anti-Corrosion Water Treatment," Journal of the American Water Works Association, V. 2841 (10), pp. 1500-1521, 1936.

18. D. Stark, "Lithium Salt Admixtures-An Alternative Method to Prevent Expansive Alkali-Silica Reactivity," Proceedings of the 9th International Conference on Alkali-Aggregate Reaction in Concrete, The Concrete Society, 1992.

19. "Standard Test Method for Petrographic Examination of Aggregates for Concrete," ASTM Designation: C 295.

20. "Standard Test Method for Potential Alkali Reactivity of Carbonate Rocks for Concrete Aggregates," ASTM Designation: C 586.

21. "Test Method for Length Change of Concrete Due to Alkali Carbonate Rock Reaction," ASTM Designation C 1105.

22. "Non-Structural Cracks in Concrete," Concrete Society Technical Report No. 22, The Concrete Society, London, 1982.

23. N.J. Carino and J.R. Clifton, "Prediction of Cracking in Reinforced Concrete Structures," NISTIR 5634, National Institute of Standards and Technology, Gaithersburg, MD, 1995.

24. J.R. Clifton and L.J. Kaetzel, "Expert Systems for Concrete Construction," Concrete International, pp. 19-24, November, 1988 . 
Table 1: Major Degradation Processes of Concrete

Degradataion
Processes

sulfate attack

Corrosion

Alkali-aggregate

Acid attack

Freeze-thaw

Leaching

\section{Concrete}

Tricalcium aluminate, Calcium hydroxide

Chloride content, pH Calcium hydroxide

$\mathrm{K}_{2} \mathrm{O} \& \mathrm{Na}_{2} \mathrm{O}$

Mineralogy of aggregate

pH, Calcium, hydroxide

Air void spacing Strength

Soluble salts

\section{Environmental ${ }^{\mathrm{b}}$}

sulfate ions

Chloride ions, $\mathrm{O}_{2}$ $\mathrm{CO}_{2}$ stray currents

Water

Acid concentrations

Water, temperature

Chemistry and flow rate of water

a Properties of concrete affecting degradation processes.

b Chemical species or factors in the environment affecting degradation processes. 
Table 2. Effect of diffusivity and $\left[\mathrm{C1}^{-}\right]$on Service Life of Reinforced Concrete (Years) ${ }^{a}$

Chloride Ion Diffusion Coefficient, $D\left(\mathrm{~m}^{2} / \mathrm{s}\right)$

Cover

(mm)

$\underline{5 \times 10^{-11}}$

$\underline{5 \times 10^{-12}}$

$\underline{5 \times 10^{-13}}$

25

0.56

5.6

56

50

2.3

23

230

75

5

50

500

100

9

90

900

400

144

1440

14,400

${ }^{a}$ Based on setting $C_{t} / C_{o}=0.55\left(C_{t}\right.$ is $\mathrm{Cl}^{-}$threshold concentration and $\mathrm{C}_{\circ}$ is $\mathrm{Cl}^{-}$concentration at concrete surface; and thickness of concrete element is $300 \mathrm{~mm}$ ).

Figure Captions

1. Effect of tricalcium aluminate $\left(C_{3} A\right)$ on expansion of mortar bars exposed to solution of 5\% concentration (by mass) of sodium sulfate.

2. Schematic of sulfate attack model for mortar bars.

3. Schematic of conceptual model of corrosion of steel reinforcement in concrete. 

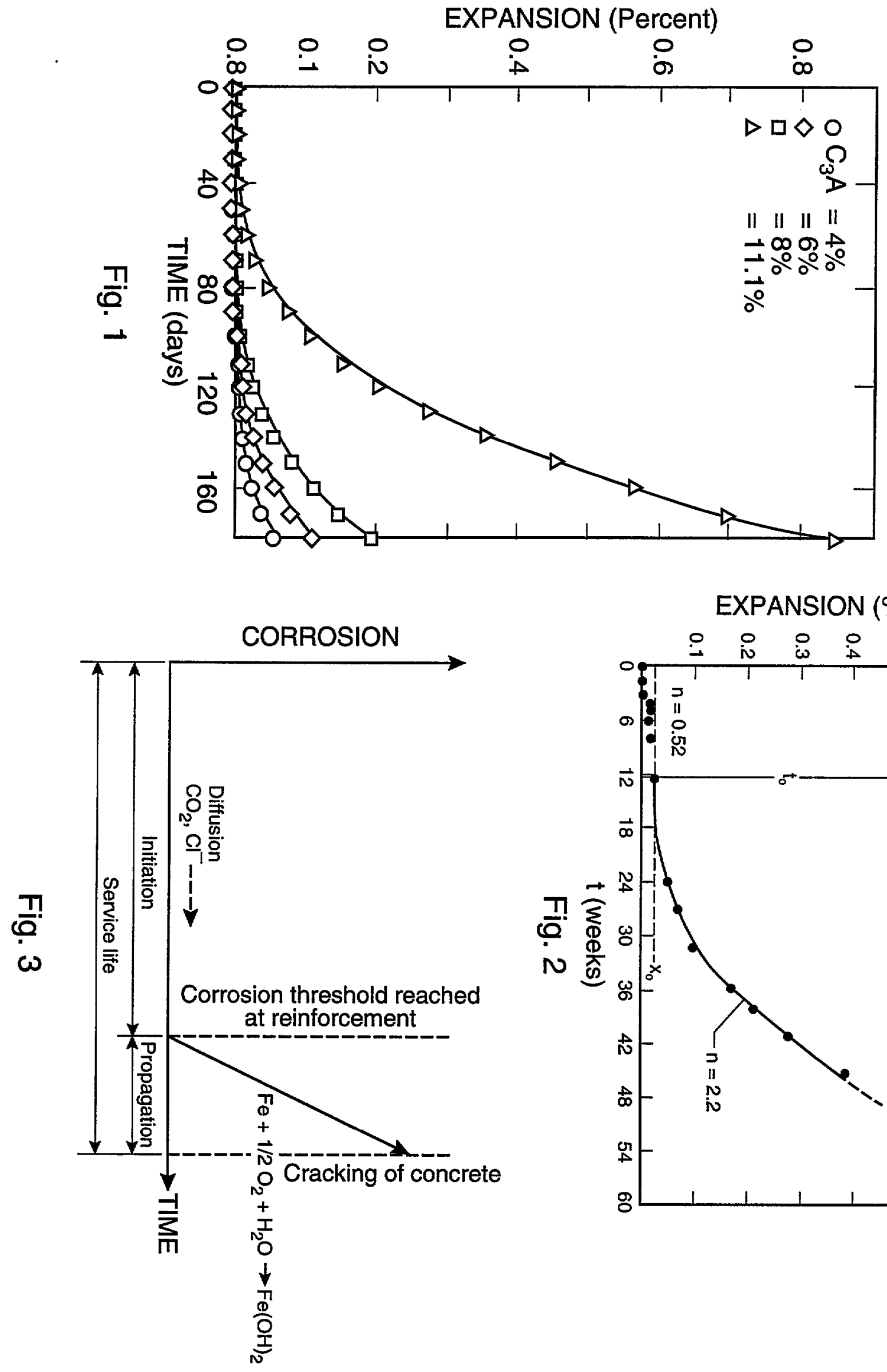

EXPANSION (\%)

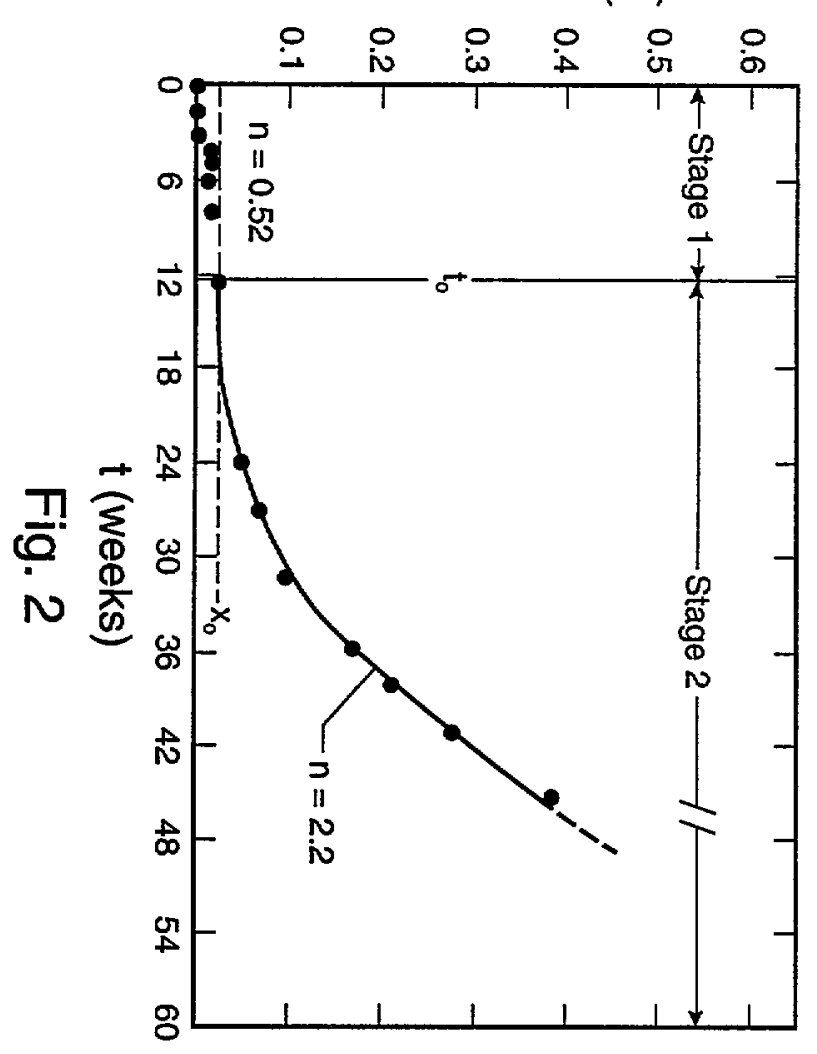

